\title{
Mudanças climáticas e convivência com o semiárido na agenda pública do Seridó Potiguar ${ }^{1}$
}

\author{
Climate change and association with the semiarid in public agenda of Seridó Potiguar
}

\author{
Cimone Rozendo ${ }^{2}$
}

\begin{abstract}
Resumo
$\mathrm{O}$ artigo analisa como o tema das mudanças climáticas vem sendo incorporado à agenda pública na região do Seridó Potiguar, estado do Rio Grande do Norte, Brasil. Tomando como referência empírica cinco municípios dessa região, um deles identificado, inclusive, pelo Ministério do Meio Ambiente (2005) como núcleo de desertificação, o artigo mostra como o tema da mudança climática ainda é marginal no âmbito do Estado e das organizações da sociedade civil. Mesmo concebendo as estratégias de convivência com o semiárido e/ou ações de combate à desertificação como temas correlatos às mudanças climáticas, estes ainda tomam lugar marginal na agenda pública e encontram-se desarticulados das demais ações estatais, a exceção da política de 1 Milhão de Cisternas. Apesar da severidade das condições climáticas, sobretudo com a seca dos últimos quatro anos, considerada uma das piores dos últimos 40 anos, as práticas de enfrentamento dessas condições por parte do Estado ainda são frágeis diante da gravidade e urgência do problema.
\end{abstract}

Palavras-chave: Mudanças climáticas; convivência com o semiárido; estado.

\begin{abstract}
The article examines how the issue of climate change has been incorporated into the public agenda in the Potiguar Seridó region, state of Rio Grande do Norte, Brazil. Taking as empirical reference five municipalities of this region, one of them identified even by the Ministry of the Environment (2005) as desertification core the article shows how the issue of climate change is still marginal within the state and civil society organizations. Even designing strategies for coexistence with the semi-arid and / or to combat desertification actions related topics as climate change they still take marginal place on the public agenda and are disjointed from other state actions, with the exception of the Policy 1 Million Cisterns. Despite the severity of climate conditions, in particular the drought in the last four years, considered the worst in 40 years, coping practices of these conditions by the state are still fragile given the gravity and urgency of the problem.
\end{abstract}

Keywords: Climate change, coexistence with the semi-arid, state.

\footnotetext{
${ }^{1}$ A parte introdutória foi parcialmente trabalhada no artigo de ANDRADE et al. "A vulnerabilidade e a resiliência da agricultura familiar em regiões semiáridas: o caso do Seridó Potiguar”. Revista Campo território, v. 8, n. 15, 2013.

2 Professora do Departamento de Ciências Sociais da Universidade Federal do Rio Grande do Norte e dos Programas de Pós-Graduação em Ciências Sociais - PPGCS e Desenvolvimento e Meio Ambiente - Prodema. E-mail: cimone.rozendo@gmail.com.
} 


\section{Introdução}

Nas regiões áridas e semiáridas dos países em desenvolvimento, as variações no clima são a principal fonte de flutuação na produção de alimentos (SIVAKUMAR et al., 2005). Nessas regiões, a vulnerabilidade às consequências das variações climáticas existentes já são um grave problema que limita o desenvolvimento da agricultura e da criação de animais (RIBOT, 1996).

A ocorrência das mudanças climáticas pode causar transformações significantes para as regiões semiáridas, promovendo a "aridização" das terras, perda da biodiversidade e redução da disponibilidade de água - prejudicando, consequentemente, as populações agrícolas que dependem da qualidade dos recursos naturais (MARENGO, 2008). Nesse sentido, a agricultura desenvolvida nas regiões semiáridas é ainda mais vulnerável aos riscos e impactos das mudanças climáticas (SMIT e SKINNER, 2002).

No entanto, é importante entender que a vulnerabilidade de uma região não acontece apenas por causa das questões climáticas - trata-se de uma conjuntura de processos e eventos físicos, sociais e político-econômicos que contribuem para a ocorrência de perdas econômicas, fome e miséria (SIVAKUMAR et al., 2005). Assim, tanto a vulnerabilidade quanto a marginalidade sociogeográfica, as mudanças climáticas e a degradação das terras secas consistem em problemas crônicos que se encontram interligados (RIBOT, 1996). Portanto, uma análise da vulnerabilidade aos eventos climáticos deve incluir essa perspectiva multicausal, colocando o clima como um agente causal entre outros. Como concebido neste trabalho.

No Nordeste brasileiro, a maior parte da população rural concentra-se na região semiárida, marcada pela aridez do clima, pela deficiência hídrica, chuvas poucas, esparsas e imprevisíveis, bem como pela presença de solos rasos e de baixa fertilidade orgânica, fatores que difícultam a produção agrícola (SILVA, 2006). Além disso, nessa região encontram-se os mais baixos indicadores socioeconômicos do Brasil (IBGE, 2010), agravando sobremaneira esse cenário. Para Ribot (1996), essa vulnerabilidade não é causada pela variação ou mudança climática apenas; ela é um resultado da configuração das forças que modelam a habilidade das populações agrícolas e pastoris de produzir, reproduzir e se desenvolver (1996).

Com o advento das mudanças, é previsto que ocorra na região semiárida do Nordeste uma escassez nas chuvas ainda maior - e que a dispersão interanual se torne mais variada. No entanto, mesmo que não haja alterações na precipitação, com o aumento das temperaturas a evaporação das águas dos lagos, açudes e reservatórios será maior, causando graves consequências para o 
desenvolvimento da região e tornando a agricultura de sequeiro, praticada por um grande contingente de agricultores, ainda mais inviável (NELSON et al., 2007; MARENGO, 2008).

Segundo Marengo (2007), os agricultores com menos recursos, como os agricultores de subsistência, com menor capacidade de se adaptar, são os mais vulneráveis às consequências das alterações climáticas. Além disso, a produção agrícola aliada a outras atividades não sustentáveis, como a agricultura de corte e queima (que converte remanescentes de vegetação em culturas de ciclo curto), o corte de madeira para a lenha, a caça de animais e a contínua remoção da vegetação para a criação de bovinos e caprinos têm levado ao empobrecimento ambiental, em larga escala, da Caatinga - bioma característico da região semiárida do Nordeste (LEAL et al., 2005). Estudos sobre os impactos das mudanças climáticas nos biomas brasileiros apontam que a Caatinga - que abriga flora e fauna únicas e espécies endêmicas e é o único exclusivamente brasileiro - está entre os mais vulneráveis no cenário de aumento das temperaturas globais, o que representa um forte fator de pressão para a desertificação da região (NOBRE, 2011).

As consequências regionais das mudanças climáticas não podem ser previstas com confiança ainda. No entanto, alguns impactos são prováveis: redução na disponibilidade de água; clima mais seco; desaparecimento da curta estação chuvosa; aumento da evapotranspiração, que acarretará na diminuição da água de lagos, açudes e reservatórios (estima-se que a redução de água nos aquíferos nordestinos pode chegar a 70\% até o ano de 2050); maior ocorrência de chuvas torrenciais e enchentes; maior frequência de dias secos consecutivos e de ondas de calor decorrente do aumento na frequência de veranicos; inviabilidade da agricultura de subsistência; migração em massa; substituição da Caatinga por vegetação típica das zonas áridas, como as cactáceas; extinção de 20 a 30\% das espécies de plantas e animais; dentre outros (MARENGO, 2008; IPCC, 2007).

Uma das proposições de Marengo (2008) para enfrentar tais problemas é o apoio às investigações científicas, por meio da integração de várias áreas do conhecimento, com a finalidade de construir cenários para as próximas décadas. As análises apresentadas aqui cumprem parte dessa proposição, uma vez que elas são fruto da pesquisa "Mudanças Climáticas, Produção e Sustentabilidade: Vulnerabilidade e Adaptação em Territórios do Semiárido da Rede Clima”, que está sob a coordenação Nacional do Inpe - Instituto Nacional de Pesquisas Espaciais - e envolve pesquisadores de várias universidades brasileiras. Embora a abrangência do projeto se dê em quatro regiões semiáridas no Nordeste do Brasil, neste artigo foram discutidos especificamente os resultados obtidos na região do Seridó Potiguar, apontada como uma das áreas mais vulneráveis às mudanças climáticas (MARENGO, 2008) no território brasileiro, inclusive contendo um dos quatro núcleos de desertificação existentes no Brasil, conforme identificado no documento do PAN Brasil 
- Programa de Ação Nacional de Combate à Desertificação e Mitigação dos Efeitos da Seca (MMA, 2005).

O propósito deste artigo foi analisar de que forma o debate sobre mudanças climáticas está sendo incorporado à agenda pública dessa região e quais práticas estão sendo levadas a cabo a partir dessa orientação. Por essa razão, as reflexões se pautaram no papel das instituições públicas nesse processo, buscando identificar as principais ações desencadeadas por elas sob a perspectiva das mudanças climáticas.

Os dados discutidos aqui resultaram da pesquisa de campo realizada no ano de 2011 e 2013 com entrevistas semiestruturadas com atores locais (prefeitos, secretários da agricultura e meio ambiente, membros de sindicatos e associações e outras lideranças locais) em quatro municípios da região do Seridó Potiguar, Caicó, Parelhas, Lagoa Nova e Acari. Os referidos municípios foram escolhidos por representarem a diversidade de condições socioeconômicas e climáticas da região.

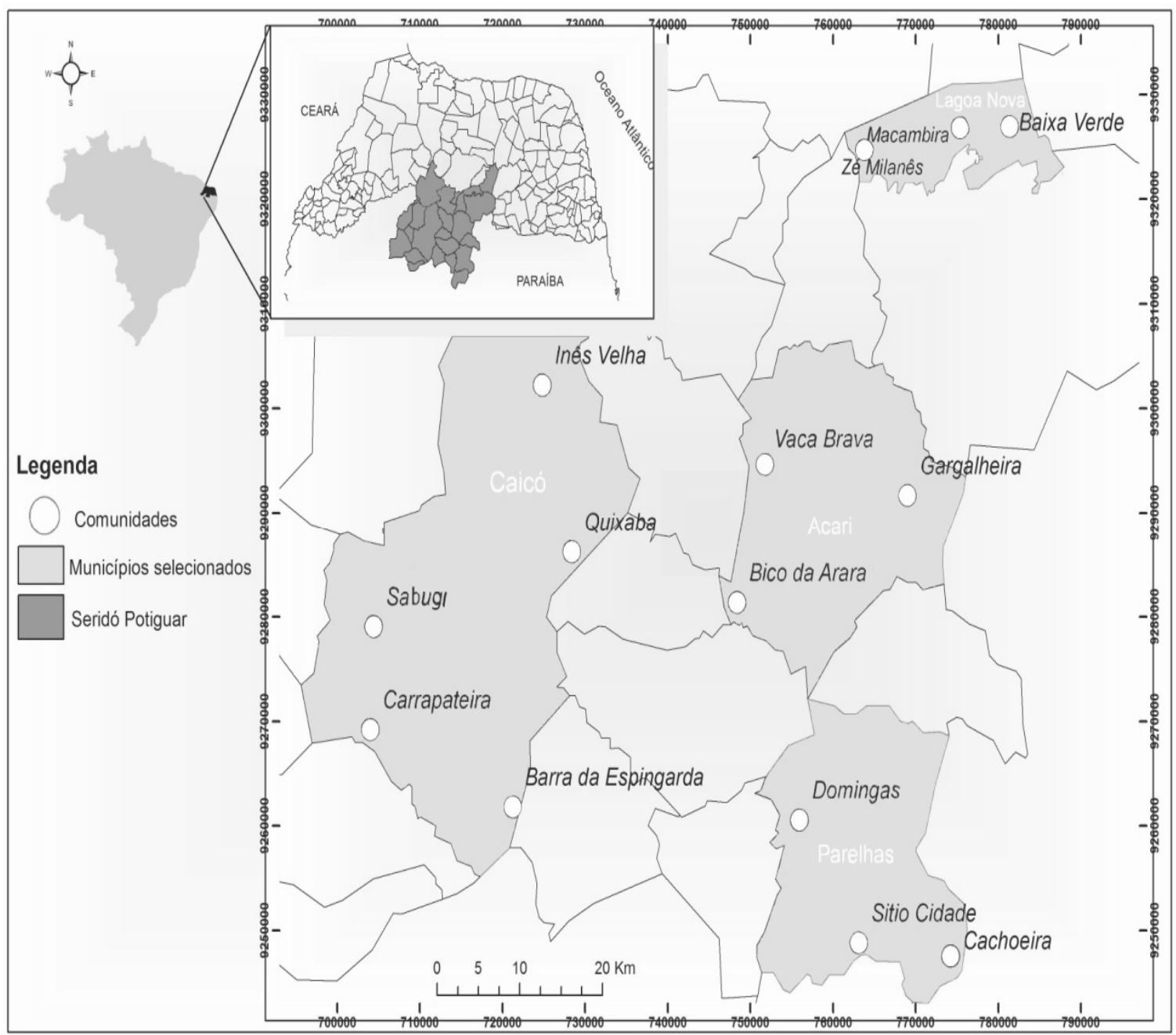

Figura 1. Localização do Seridó Potiguar segundo a delimitação de Morais (2005) e municípios da pesquisa. Fonte: Elaborado por Antônia Vilaneide Costa Lopes de Oliveira. 


\section{O ponto de partida: Afinal o que se entende por política pública de mudança climática?}

Em sua obra “A política pública da mudança climática”, Giddens (2009) afirma de maneira contundente que as nações não dispõem de políticas públicas com foco nas mudanças climáticas. Para o autor, as razões disso são inúmeras: a divergência de opiniões sobre níveis de emissões, tema sempre delicado, haja vista as resistências dos países na assinatura do Protocolo de Kyoto; as possibilidades de desaceleração econômica; a necessidade de mudanças nos estilos de vida; enfim, uma miríade de situações que de certo modo exigiriam um esforço individual e coletivo que nem todos parecem estar dispostos a enfrentar, sobretudo os países mais industrializados. Além do mais, para as nações cujos patamares de desenvolvimento não conseguiram assegurar uma existência digna, esse tema parece concorrer com necessidades mais emergenciais. Apesar do aspecto nebuloso da questão, o autor acredita ser preciso tomar medidas urgentes a esse respeito, a começar pela sensibilização das pessoas com o tema. Dentre as estratégias sugeridas por Giddens (2010), pode-se destacar, de modo geral: a) uma mudança no enfoque de mudança climática para política energética; b) um novo posicionamento do Estado (em seus diferentes níveis) como agente assegurador dessas políticas; c) um papel mais ativo dos mercados que não se restrinja a área de comércio de emissões; d) o desenvolvimento de capacidades adaptativas que possam se antecipar ao problema e não apenas adaptar-se a eles; e) investimentos em recursos energéticos renováveis.

Se essas referências são tomadas em conjunto, dificilmente se poderá fazer uma análise da política de mudança climática no Brasil, mas talvez seja possível falar de ações ou estratégias que, embora não tenham como eixo estruturante a mudança climática, incidam sobre ela. Sob esse aspecto, as estratégias de acesso à água nas regiões semiáridas, o combate à desertificação, a convivência com o semiárido, desenvolvidas mais recentemente, tanto por parte da sociedade civil quanto por parte do governo brasileiro, aproximam-se desse objetivo, como se verá adiante. Mesmo não sendo possível trabalhar com a totalidade da perspectiva proposta por Giddens (2010), dois aspectos balizaram as análises contidas aqui: a sensibilização das pessoas para o tema da mudança climática e o papel do Estado como agente assegurador dessas políticas.

\section{A caracterização da área de estudo}

O Seridó Potiguar representa um fragmento regional localizado da Mesorregião Central do Rio Grande do Norte e abrange uma área de $9.186,7 \mathrm{~km}^{2}$ (IBGE, 2010). Para o presente estudo, foi 
adotada a regionalização do Seridó definida por Morais (2005), na qual o recorte regional delimitado corresponde ao Seridó "historicamente construído" através de uma relação espaçotemporal "impregnada de conteúdo político, econômico e cultural" onde se manifestam os sentimentos de pertencimento e identidade da população, sendo o Seridó, assim, representado por 23 municípios - Caicó, Acari, Jardim do Seridó, Serra Negra do Norte, Currais Novos, Florânia, Parelhas, Jucurutu, Jardim de Piranhas, São João do Sabugi, Ouro Branco, Cruzeta, Carnaúba dos Dantas, Cerro Corá, São Vicente, São Fernando, Equador, Santana do Seridó, São José do Seridó, Timbaúba dos Batistas, Lagoa Nova, Ipueira e Tenente Laurentino Cruz (MORAIS, 2005, p. 26-7).

Segundo dados do IBGE (2010), a população total do Seridó é de 279.492 habitantes, sendo que 216.778 moram nas zonas urbanas e uma parcela menor, 62.714 habitantes, reside nas zonas rurais. Na região existem 9.970 estabelecimentos caracterizados como de agricultura familiar, o que representa $80,6 \%$ dos estabelecimentos agrícolas da região. Esses, porém, ocupam apenas 24,2\% da área total, somando 145.075 ha. Dessa área, 15.797 ha (10,8\% do total) são ocupados por lavouras temporárias, outras 7.855 ha $(5,4 \%)$ por lavouras permanentes e a maior parte, 72.397 ha $(49,9 \%)$, por pastagens. A região foi ocupada historicamente pela pecuária extensiva, pela cultura do algodão, pelas lavouras de subsistência e atividades de mineração. Com a decadência das lavouras de algodão, a pecuária foi ampliada e outras atividades ganharam força, como foi o caso da indústria ceramista, cujo impacto sobre os recursos naturais na região tem sido bastante negativo. Segundo relato de um dos técnicos da Articulação do Semi Árido (ASA) são 52 indústrias ceramistas nessa área.

Além do assoreamento dos rios em função da retirada da argila, a atividade demanda uso intenso de lenha, comprometendo sobremaneira os recursos florestais da região, já degradados pelas atividades mencionadas anteriormente. Segundo Silva (2006) citado por PTDRS (SEPLAN, 2000), a cerâmica é responsável por “[...] 69,7\% do total de lenha extraída para fins energéticos”. Essa atividade associada à pecuária tem sido a razão da diminuição da produção de alimentos na região, uma vez que se estendem às áreas de várzea, anteriormente utilizadas para o cultivo de milho, feijão e outros gêneros alimentícios, conforme identificado em pesquisa de campo.

O Seridó Potiguar está inserido na região semiárida do Nordeste brasileiro e, por isso, encontra-se naturalmente exposto a riscos relacionados ao clima da região, que afetam diretamente a disponibilidade de água, dando lugar à "ocorrência de secas totais (quando afetam toda a região) ou parciais, de duração anual (quando ocorrem em anos intercalados) ou plurianual (quando se estendem por períodos superiores a um ano) (SEPLAN, 2000, p. 28). Como dito anteriormente, a região possui um dos núcleos de desertificação identificados pelo Ministério do Meio Ambiente. A 
área que compreende os municípios de Acari, Carnaúba dos Dantas, Cruzeta, Currais Novos, Equador e Parelhas corresponde a uma extensão territorial de 2.792,39 km², abrigando uma população de 91.673 habitantes.

De acordo com o Plano Territorial de Desenvolvimento Rural Sustentável do Seridó (PTDRS), a temperatura média anual da região situa-se entra 26 e $28^{\circ} \mathrm{C}$, a insolação é de 3.240 horas/ano, a umidade relativa do ar gira em torno de $64 \%$ e a precipitação pluviométrica média anual varia entre 645 e $750 \mathrm{~mm}$, com uma taxa alta de evapotranspiração. A estação chuvosa é curta e concentrada entre os meses de janeiro e maio ( $87 \%$ do total de precipitação total do ano), com chuvas esparsas e irregulares, e há probabilidade de ocorrência de enxurradas (MEDEIROS, 2004; DUQUE, 2004). A região apresenta elevada deficiência hídrica, principalmente nos meses entre junho e dezembro (SANTOS et al., 2010). Não há meses de excedente hídrico; apenas entre fevereiro e abril a região apresenta valores de deficiência hídrica iguais a zero na maior parte dos municípios (SANTOS et al., 2010).

Também de acordo com o PTDRS (2010), a alta taxa de evapotranspiração é responsável por outro problema característico da região: a salinização das águas dos mananciais - "processo que ocorre nos terrenos cristalinos por conta da intensa ação do sol e dos altos índices de evaporação, associados aos ventos" - que prejudica a qualidade da água e inviabiliza o seu uso para consumo humano, animal e na agricultura.

Do ponto de vista social, a população seridoense é reconhecida por sua forte identidade cultural e capacidade organizativa. Essas características estão fortemente ligadas à presença de organizações de base da Igreja Católica, por meio das comunidades eclesiais de base (CEBs). Segundo relato de uma das lideranças dos movimentos sociais, mais 500 associações foram registradas apenas entre 1996 e 2002. Em razão dessa capacidade organizativa, as instituições conseguiram mobilizar uma diversidade de projetos. Só a Agência de Desenvolvimento Sustentável do Seridó (Adese - uma Oscip) e o Ceapac - Centro de Apoio aos Projetos Alternativos Comunitários - acompanharam mais de 78 projetos, como os de adutoras para comunidades rurais, açudes ou poços, energia rural, telefonia rural, transporte na área rural, profissionalização dos jovens por meio de cursos técnicos.

Guaju, Matinhos, v. 1, n. 1, p. 90-105, jan./jun. 2015 


\section{A convivência com o semiárido como uma política de mudança climática}

Em sua obra "Entre dois paradigmas: combate à seca e convivência com o semi-árido", Silva (2003) afirma que foi no final de 1990 que se começou a forjar uma nova compreensão sobre as formas de se relacionar com o fenômeno das secas. A proposição de convivência com o semiárido, cunhada a partir do debate público sobre o problema, representava a contraposição à noção de combate à seca, advinda de uma visão reducionista e tecnicista do governo federal e apropriada pelas elites locais. Segundo este autor:

A construção da proposta de convivência com o semi-árido tem sua gênese nas iniciativas de centros de pesquisa, como a Embrapa, e das organizações nãogovernamentais que vêm desenvolvendo projetos nas áreas de recursos hídricos, produtivas e socioculturais em áreas do semi-árido brasileiro desde o início da década de 1980. A proposta ganhou impulso significativo no final da década de 1990, com a criação da Articulação no Semi-Árido (ASA), reunindo atualmente cerca de 700 organizações não-governamentais, igrejas e movimentos sociais (SILVA, 2003, p. 376).

Diferentemente da noção de combate à seca, a proposta de convivência fundamentou-se no paradigma da sustentabilidade, envolvendo noções de acesso aos direitos como à terra, à água, ao trabalho etc., formuladas com vistas ao fortalecimento da democracia e à promoção de justiça social. Essas características aparecem de forma destacada nos objetivos da ASA:

Contribuir para a implementação de ações integradas para o semi-árido; a conservação, o uso sustentável e recomposição ambiental dos recursos naturais; a quebra do monopólio do acesso à terra, água e outros meios de produção; apóia a difusão de métodos, técnicas e procedimentos que contribuam para a convivência com o semi-árido (ASA, 2001 apud SILVA, 2003, p. 377).

Contudo, o referido autor evidencia que essa reorientação ainda não conseguiu suplantar as propostas de combate à seca e que ambas são articuladas e apropriadas de diferentes modos pelos atores sociais nesse território. Neste quadro, o enfrentamento das mudanças climáticas parece metamorfoseado à luta diária por encontrar os caminhos para essa convivência.

\section{As instituições e as estratégias de convivência como derivações da política de mudança climática}

Guaju, Matinhos, v. 1, n. 1, p. 90-105, jan./jun. 2015 
No Plano Territorial de Desenvolvimento Sustentável do Seridó (SEPLAN, 2008), documento em que constam o diagnóstico da região e as propostas de ações para a área, as mudanças climáticas aparecem referenciadas apenas de forma sumária. Nesse documento não aparece de forma evidente a relação das ações de convivência com o problema mais geral das mudanças climáticas. Essas se constituem mais como um pano de fundo do problema da desertificação, por exemplo, do que um problema específico. Isso revela que o eixo estruturante das ações que podem repercutir positivamente para a política de mudanças climáticas ou convergir para ela, nesse território está nas políticas de convivência com o semiárido que se expressam sob formas diversas, seja na criação de infraestrutura (cisternas, adutoras), seja na proposição de sistemas produtivos mais adequados à realidade e na valorização do saber local como fundamento do paradigma da convivência com a seca. Um fator importante nesse contexto é que grande parte das ações pensadas sob esse enfoque emana da sociedade civil, particularmente por meio da ASA Articulação do Semiárido, citada anteriormente.

A ideia de mudança climática aparece com destaque no documento do PAN Brasil Programa de Ação Nacional de Combate à Desertificação e Mitigação dos Efeitos da Seca (MMA, 2005). Lançado em 2004, o referido documento contempla as diretrizes do compromisso assumido pelo Brasil na Convenção das Nações Unidas de Combate à Desertificação (CCD). As estratégias do PAN se orientam por quatro eixos: 1) Redução da pobreza e desigualdade; 2) Ampliação sustentável da capacidade produtiva; 3) Conservação e preservação do manejo sustentável dos recursos naturais; e 4) Gestão democrática e fortalecimento institucional. Apesar da abrangência dos objetivos do documento, poucas ações foram efetivamente implantadas até a época da realização da pesquisa. Apenas as ações do primeiro eixo tiveram maior expressão, através das políticas de distribuição de renda como a do Bolsa Família e a ampliação do acesso à previdência, conforme pesquisa de campo. Também em destaque a Política de 1 Milhão de Cisternas, que se encontrava em plena expansão na época da pesquisa.

Em entrevistas com representantes do poder público municipal das áreas estudadas, quase a totalidade deles foi incapaz de identificar alguma ação desenvolvida pelo Estado com foco nas mudanças climáticas. Apenas um prefeito citou um convênio que estava em curso com empresas eólicas como uma ação correlata ao tema. Mesmo as políticas de convivência com o semiárido não foram sequer citadas pelos representantes do poder local. Supôs-se que a Emater teria um papel fundamental no quadro das estratégias de convivência com o semiárido e/ou mudanças climáticas, já que é a responsável estatal pelo fornecimento de assistência técnica aos agricultores. Contudo, a pesquisa revelou uma situação de muito alheamento em relação ao tema e fragilidade estrutural para 
lidar com as questões mais simples do cotidiano da assistência técnica. A Emater encontra-se imensamente sucateada. Além de falta de infraestrutura física e recursos humanos limitados, a instituição vem paradoxalmente assumindo funções diversas no âmbito da extensão rural, como as de educação no campo, a inspeção agropecuária (anteriormente realizadas pelo Idiarn - Instituto de Defesa e Inspeção Agropecuária) e inúmeras representações nos conselhos locais. Um único técnico chega a fazer parte de quatro conselhos diferentes (saúde, educação, agricultura etc.). Também é comum os cargos das secretarias de agricultura dos municípios serem ocupados por técnicos dessa instituição, diminuindo ainda mais a capacidade de prestação de assistência técnica já tão limitada. Essa sobrecarga de trabalho é concebida como uma das causas para o não desenvolvimento de estratégias ou de discussões que coloquem o tema das mudanças climáticas na ordem do dia. Mesmo o debate sobre a desertificação, que vem ganhando força nos cenários mundial e nacional, encontra-se bastante limitado no âmbito da instituição.

Sobre a incorporação do tema das mudanças climáticas na agenda pública, os relatos dos extensionistas da Emater, por exemplo, atestam que essa discussão está praticamente ausente de seu cotidiano de trabalho, embora quase todos os técnicos aleguem perceber seus efeitos. Apenas a política do "Garantia Safra” é associada pelos técnicos ao tema. O Garantia Safra é um programa do governo federal, executado pelo Ministério do Desenvolvimento Agrário, que prevê indenização para os agricultores que tiveram perdas superiores a $50 \%$ da safra, seja por excesso de chuvas ou por secas. Segundo o MDA (2013), "é mais uma ação importante para potencializar o plano de convivência com o semiárido". No entanto, os técnicos sublinham o caráter limitado e paliativo da ação, uma vez que ela se restringe a uma parcela muito pequena de agricultores e somente em situações emergenciais. O técnico explicou que em seu município, com 3 mil agricultores, quase todos foram afetados pela seca, mas o seguro cobriria somente 44 deles. Isso evidenciava fortemente os limites da estratégia frente às dimensões do problema. $\mathrm{O}$ caráter seletivo dessas ações aparece revelado em outros depoimentos:

Hoje, quase todos os projetos existentes no Seridó, seja de instituições públicas ou de instituições não governamentais, têm como público prioritário os agricultores familiares, no entanto, os recursos não chegam para esses que deveriam ser os beneficiários. Apesar do grande número de agricultores familiares na região, os projetos não conseguem quebrar a lógica de alcançar sempre aqueles que estão melhor organizados em alguma cadeia produtiva (Entrevista, gestor do Comitê de Bacias Piranhas-Açu, maio-2013). ${ }^{3}$

\footnotetext{
${ }^{3}$ Entrevista gentilmente cedida pelo colega Fernando Bastos Costa, do Departamento de Políticas Públicas da UFRN, cuja pesquisa se destina a compreender o papel das instituições no Seridó no que concerne à questão ambiental.
} 
Essa característica faz com que seja suplantada a equidade pretendida pelas ações que se fundamentam na perspectiva de convivência, reforçando entre os agricultores as disparidades já presentes na região.

Como dito anteriormente, apenas o plano de garantia da safra e as ações de abastecimento d'água por meio dos carros pipas são vinculados por eles a uma política de mudança climática. Nem mesmo a Política de 1 Milhão de Cisternas foi mencionada. Os relatos evidenciam que as estratégias são pontuais e emergenciais, colocadas em curso quase sempre nos momentos de crise e raramente de maneira preventiva. Como também mostra Silva (2003)

De modo geral, as ações governamentais de intervenção nessa realidade foram sendo construídas com base nas seguintes características: a) o caráter emergencial, fragmentado e descontínuo dos programas desenvolvidos em momentos de calamidade pública; b) as ações emergenciais que alimentam a "indústria da seca"; e c) a solução hidráulica, com a construção de obras hídricas, quase sempre favorecendo empreiteiras e a grande propriedade rural. Em todas essas características reproduz-se o uso político do discurso da miséria e do subdesenvolvimento como decorrência direta das secas (SILVA, 2003, p. 369).

Afirmou-se anteriormente que essa região possui um número elevado de associações, cooperativas, ONGs, cujos princípios se orientam pelo paradigma de convivência com a seca, mas por que essas instâncias têm dificuldades em incorporar temas como os das mudanças climáticas e mesmo da desertificação?

Sobre esse aspecto, Hannigan (1997) afirma que o reconhecimento de um problema enquanto tal não tem um percurso simples. Embora muitas vezes ele seja constatado, sua apreensão envolve o trabalho dos expertises (a evidência científica) até um intenso processo de publicização (marketing) e convencimento do público em geral para posterior adesão a uma agenda pública. É a articulação desses processos que transforma o tema num problema. Esse aspecto parece particularmente caracterizado na região estudada. Em todos os documentos oficiais a desertificação tem um peso muito grande, no entanto, as lideranças locais afirmam que as estratégias de enfrentamento ainda são pontuais considerando as dimensões do problema. Segundo um dos membros da ASA:

Há um vazio de educação de convivência com o semiárido. Aqui não podemos ter o mesmo uso que em outras regiões. Algodão, pecuária e mineração são culturas devastadoras [....] Mata e desmata. Essa é a cultura que povoou essa região... que é a cultura burguesa. No campo ambiental, nós temos uma dívida imensa. Se você vê uma preá quer matar... essa cultura é muito forte ainda. Nossas ações ainda com a convivência são muito frágeis. São ações muito pontuais. Só para ter uma ideia, nós temos 52 indústrias ceramistas nessa área (Entrevista maio de 2013). 
Destaca-se também que há por parte das lideranças, e mesmo do público em geral, posicionamentos distintos, tanto sobre as mudanças climáticas quanto sobre os processos de desertificação, e que estes temas nem sempre parecem correlatos. Quando os agricultores foram indagados se já haviam ouvido falar em mudanças climáticas, segundo Andrade (2013, p. 87):

Entre os 241 entrevistados, $55,2 \%$ deles afirmaram conhecer o termo, embora $14,5 \%$ desse total não soubessem definir seu significado. Os que apresentaram alguma resposta, em geral relacionaram as mudanças climáticas ao desmatamento, à poluição, aos danos ao meio ambiente e ao "clima esquentando" - enquanto alguns imputaram o problema a causas religiosas como "fim dos tempos".

Paradoxalmente, o termo desertificação parece mais distante da vida dessa população do que o de mudanças climáticas. Há num certo aspecto uma negação do problema, uma vez que muitos se veem diretamente implicados nesse processo. No município de Parelhas, por exemplo, uma grande quantidade de agricultores se dedica também à atividade ceramista. Ela é a estratégia que substitui a atividade agrícola nos tempos de estiagem. Questionar isso seria colocar em questão as poucas opções de trabalho na região. Como explica uma das lideranças e gestor do comitê de bacias :

As pessoas pressionam os recursos naturais como a última opção. Se elas tivessem incentivo, não precisariam fazer isso. Os municípios até querem fazer alguma coisa na área ambiental. Se criam os conselhos, mas eles não têm força. É o setor menos importante de um modo geral. Não existe uma política nessa área, nem no município, nem no Estado (Entrevista, gestor do Comitê de Bacias Piranhas-Açu, maio-2013).

Em uma região onde a população é sucessivamente submetida a diferentes formas de exclusão, a desertificação é concebida como uma criação do Estado para justificar a expulsão das pessoas dessa localidade. Como sugere o relato a seguir:

Esse assunto aqui é muito novo... Eu não acredito que o Seridó tenha desertificação. Eu sou geógrafo e não acredito nisso... Se você plantar hoje nas áreas dá! As pessoas não aceitam dizer que existe! Acho que no processo futuro talvez... O que eu vejo são pessoas vivendo lá com seus animais. Lá tem vida... Enquanto tiver vida, não tem desertificação (Entrevista, gestor do Comitê de Bacias Piranhas-Açu, maio-2013).

Parte dessa percepção que busca negar os fatos deriva das experiências históricas das relações entre os movimentos sociais da região e Estado. Embora muitas das ações advindas dos movimentos sociais tenham sido encampadas pelo Estado, a tal ponto de virar uma política pública, 
como no caso da Política de 1 Milhão de Cisternas isso não se deu sem conflito. Nesse exemplo, o conteúdo social e de mobilização que marcou a implementação da política acabou sendo subvertido ao longo de sua execução. A construção das cisternas era feita em sistema de mutirão ou com mão de obra contratada na própria região onde seria instalada com o propósito de fortalecer laços de solidariedade, garantir emprego e dinamizar a economia local. Também o material para confecção era adquirido na localidade. Houve um grande trabalho de afinamento político entre as instituições que compõem a ASA para articular essa política, já que há internamente à organização entendimentos distintos sobre os encaminhamentos dessa proposta, como mostra Malvezzi (2013). Além disso, garantir um diálogo com o governo nesses termos foi uma conquista muito importante. Contudo, a partir de 2012, cedendo o lobby das indústrias, o governo federal decidiu adquirir cisternas de polietileno, desarticulando os objetivos iniciais da política e colocando mais uma vez sob suspeição as ações do Estado. A transformação dessa tecnologia em política pública também teve seus limites. Os representantes dos movimentos sociais acabaram assumindo funções que não se relacionavam de nenhum modo aos propósitos de sua organização. A esse respeito uma das lideranças esclarece:

A tecnologia social das cisternas, por exemplo, foi uma luta da sociedade civil e que foi universalizada por uma política de governo. Isso foi bom, mas essa apropriação teve seus custos, uma vez que agora nós viramos cumpridores de metas e não mais pensamos as nossas práticas (Entrevista com membro da ASA, maio-2013).

Esse problema se reproduz também em outras esferas, como na gestão do Comitê de Bacias da Região, espaço fundamental na implementação da política de recursos hídricos.

O Comitê de Bacias ainda não conseguiu estabelecer um diálogo maior com a sociedade civil.[...] Nós tivemos momentos de reunir 200 pessoas e hoje não conseguimos reunir 60. A presidência do Comitê também está distante das bases, o que dificulta uma maior compreensão dos problemas que afligem os agricultores. O comitê ainda não conseguiu dar cabo de temas fundamentais que são de sua responsabilidade, palestras educativas sobre a questão da água, palestras com os irrigantes, os usuários, a questão de outorga d'agua. O Comitê ainda não foi visto com o papel que lhe cabe. Ele é concebido muito mais como um órgão burocrático, fiscalizador, de penalização do que como um espaço de concertação e de caráter educativo (Entrevista, gestor do Comitê de Bacias Piranhas-Açu, maio-2013).

Este e tantos outros casos, que não cabem ser mencionados aqui, evidenciam a forma dúbia de relação que o Estado mantém com as organizações dessa localidade, deixando brechas para desconfianças constantes. Em razão de histórias sucessivas de expulsão, seja pela migração forçada 
em tempos de secas, ocasião em que o Estado ou se omitiu ou agiu de maneira pouco eficaz, seja pela decadência das atividades econômicas ali implantadas, favorecidas pelo Estado, como no caso da cotonicultura, que desmantelou um grande contingente de pequenas propriedades, muitos problemas identificados na região por parte do Estado ou de expertises são concebidos como novas estratégias para expulsar as pessoas de suas terras.

Sob esse aspecto, o Estado assegurador proposto por Giddens (2009), como uma questão fundamental para a política de mudança climática, ainda está muito distante da realidade encontrada na região do Seridó. Como destaca Malvezzi (2013), “o Estado é muito contraditório em suas ações, pois ao mesmo tempo em que apoia a iniciativa da ASA, admite a cisterna de polietileno e insiste na transposição que privilegia o hidronegócio”.

Prevalecem formas de organização ortodoxas para enfrentar os problemas que exigem posicionamentos mais efetivos tanto da parte do Estado quanto da sociedade civil. As institucionalidades necessárias a esse enfrentamento ainda estão por serem construídas. A criação da ASA é uma experiência inovadora nesse aspecto e suas práticas podem futuramente inspirar outras estratégias similares a P1MC. As próprias formas de intervenção nessa realidade carecem de reorientação como bem lembrou uma das lideranças: "A leitura do homem do campo é muito diferente: de espacialidade de tempo, de tudo... Ele não reproduz o que aprende; ele cria em cima do que viu. Esse é um campo fantástico que precisamos explorar, mas não na perspectiva do capital, mas da vida" (Entrevista com membro da ASA, maio-2013).

\section{Considerações Finais}

$\mathrm{O}$ artigo evidenciou que apesar das condições de vulnerabilidade da população rural da região do semiárido do Seridó às mudanças climáticas, apontadas por toda literatura, o tema ainda não entrou na agenda pública do Estado em seus diferentes níveis (Federal, estadual e municipal) como uma questão estruturante. Mesmo considerando as políticas de convivência com o semiárido e de combate à desertificação como derivações da política de mudança climática, as estratégias desenvolvidas nessa perspectiva ainda são insuficientes e pontuais. Apesar da presença de movimentos sociais organizados nessa região, o tema da mudança climática, bem como da própria convivência com o semiárido, não vem recebendo o tratamento adequado, aspecto reconhecido inclusive pelas lideranças locais. As instituições tanto do Estado quanto dos movimentos sociais 
continuam operando a partir de formas ortodoxas que dificultam a apreensão do problema com a força que ele merece.

\section{Referências}

ANDRADE, A. J.; ROZENDO, C.; MEDEIROS, N. A vulnerabilidade e a resiliência da agricultura familiar em regiões semiáridas: o caso do Seridó Potiguar. Revista Campo Território, v. 8, n. 15, 2013.

ANDRADE, A. J. P. de; SILVA, N. M. da; SOUZA, C. R. de. As percepções sobre as variações e mudanças climáticas e as estratégias de adaptação dos agricultores familiares do Seridó potiguar. Desenvolvimento e Meio Ambiente, [S.1.], v. 31, ago. 2014. Disponível em: $<$ http://ojs.c3sl.ufpr.br/ojs/index.php/made/article/view/32955>. Acesso em: 27 jul. 2015.

BRASIL. Ministério do Meio Ambiente. Secretaria de Recursos Hídricos. Programa de ação nacional de combate à desertificação e mitigação dos efeitos da seca PAN-Brasil. Brasília: Edições MMA, 2005. 242 p.

DUQUE, J. G. O Nordeste e as lavouras xerófilas. 4. ed. Fortaleza: Banco do Nordeste do Brasil, 2004.

GIDDENS, A. A política de mudança climática. Rio de Janeiro: Zahar, 2010.

HANNIGAN, J. A. Sociologia ambiental: a formação de uma perspectiva social. Lisboa: Instituto Piaget, 1997.

MARENGO, J. A. Mudanças climáticas globais e seus efeitos sobre a biodiversidade: caracterização do clima atual e definição das alterações climáticas para o território brasileiro ao longo do século XXI. 2. ed. Brasília: Ministério do Meio Ambiente, 2007. vol. 1.

MALVEZZI, R. Semiárido: dez anos de investimentos contraditórios. Entrevista: Instituto Humanitas Unisinos, São Leopoldo - RS, 2013. Disponível em: < http://www.ihu.unisinos.br/entrevistas/519585-semiarido-dez-anosde-investimentos-contraditorios-entrevista-especial-com-roberto-malvezzi>. Acesso em: 20 jun. 2015.

MEDEIROS, G. L. D. de. A desertificação do semi-árido nordestino: o caso da região do Seridó Norte-Riograndense. Dissertação (Mestrado)- Curso de Desenvolvimento e Meio Ambiente, Universidade do estado do Rio Grande do Norte, Mossoró, 2004, 137 p.

MORAIS, I. R. D. Seridó Norte-Rio-Grandense: uma geografia da resistência. Caicó: Editora do Autor, 2005.

NELSON, D. R.; ADGER, N.; BROWN, K. Adaptation to environmental change: contributions of a resilience framework. The Annual Review of Environment and Resources, 32, p. 395-419, 2007. 
NOBRE, P. Mudanças climáticas e desertificação: os desafios para o Estado brasileiro. In: LIMA, R. C. C.; CAVALCANTE, A. de M. B.; MARIN, A. M. P. (Eds.). Desertificação e mudanças climáticas no semiárido brasileiro. Campina Grande: Instituto Nacional do Semiárido, 2011. p. 25-34.

RIBOT, J. C. Introduction. Climate variability, climate change and vulnerability: moving forward by looking back. In: RIBOT, J. C.; MAGALHÃ̃ES, A. R.; PANAGIDES, S. S. (Comps.). Climate variability, climate change and social vulnerability in the semi arid tropics. Reino Unido e Nova Iorque: Cambridge University Press, 1996. p. 1-13.

SANTOS, A. S. dos et al. Estimativa do balanço hídrico climático para a microrregião do Seridó Estado do Rio Grande do Norte. In: CONGRESSO BRASILEIRO DE METEOROLOGIA. Belém, 16, 2010. Anais. Belém: CBMET, 2010. p. 1-5.

SEPLAN. RIO GRANDE DO NORTE. IICA. Plano de desenvolvimento sustentável do Seridó. Volume 1 (Diagnóstico). Caicó - RN, 30 de setembro de 2000.

SILVA, R. M. A. Entre o combate à seca e a convivência com o semi-árido: transições paradigmáticas e sustentabilidade do desenvolvimento. Brasília, Tese (Doutorado em Desenvolvimento Sustentável) - Universidade de Brasília, 2006.

SILVA, R. M. A. Entre dois paradigmas: combate à seca e convivência com o semiárido. Sociedade e Estado. Brasilia [on-line]. 2003, v. 18, n. 1-2, p. 361-385. Disponível em: $<$ http://dx.doi.org/10.1590/S0102-69922003000100017> Acesso em: 10 outubro de 2014.

SIVAKUMAR, M. V. K.; DAS, H. P.; BRUNINI, O. Impacts of present and future climate variability and change on agriculture and forestry in the arid and semi-arid tropics. Climatic Change, New York, v. 70, n. 1, p. 31-72, 2005.

SMIT, B.; SKINNER, M. Adaptation options in agriculture to climate change: a typology. Mitigation And Adaptation Strategies For Global Change, v. 7, n. 1, p. 85-114, 2002.

Artigo recebido em 28/07/2015. Aceito para publicação em 13/09/2015. 